\title{
Bandwidth Enhancement for Microstrip Patch Antenna Using Stacked Patch and Slot
}

\author{
H. F. AbuTarboush, H. S. Al-Raweshidy and R. Nilavalan \\ Wireless Networks \& Communications Centre (WNCC), School of Engineering \& Design \\ Brunel University, West London U.K. \\ Email: Hattan.AbuTarboush@brunel.ac.uk
}

\begin{abstract}
Small size wideband microstrip patch antenna with slot in ground plane and stacked patch fed through microstrip line is presented. By inserting slot on ground plane and stacked patch supported by wall, the bandwidth can improve up to $25 \%$ without significant change in the frequency. The bandwidth before adding the slot and the stacked patch was $3.72 \%$, whereas after adding the slot and the stacked patch the bandwidth increased up to $25 \%$ ranging from 2.45 to $3.3 \mathrm{GHz}$. The radiation pattern has acceptable response at both E-plane and H-plane. The ground plane size is 30 $\mathrm{mm}$ by $90 \mathrm{~mm}$, the antenna designed is based on Roger RT/duroid 5880 with dielectric constant 2.2.
\end{abstract}

\section{INTRODUCTION}

With the rapid growth of the wireless mobile communication technology, the future technologies need a very small antenna and also the need of wide band antenna is increased to avoid using two antennas and to allow video, voice and data information to be transmitted. Microstrip patch antenna is promising to be a good candidate for the future technology. Microstrip patch antenna consists of a dielectric substrate, with a ground plane on the other side. Due to its advantages such as low weight, low profile planar configuration, low fabrication costs and capability to integrate with microwave integrated circuits technology, the microstrip patch antenna is very well suited for applications such as wireless communications system, cellular phones, pagers, Radar systems and satellite communications systems [1, 2, 3]. Several designs have been investigated and reported to decrease the size of the antenna [4] and to improve the bandwidth of the antenna [5, 6]. Handset antenna has been reported with wide bandwidth [7]. Half U-slot patch antenna with shorting wall reported in [8] with $28 \%$ impedance bandwidth. Double U-Slot patch antenna has been reported recently [9] for WiMAX applications.

In this paper, compact size wideband patch antenna with slot in ground plane and stacked patch is proposed. The bandwidth has improved by adding stacked patch and adding a slot in the ground plane. The paper is divided as: section two, presents the dimensions of the proposed antenna followed by the result of the simulated antenna. Finally, section three provides the conclusion. Results are based on a commercially available finite element package HFSS.

\section{ANTENNA STRUCTURE AND RESULTS}

The antenna has a very simple structure fed by $50 \mathrm{ohm}$ microstrip line. Fig. 1 and tab. 1 demonstrate the dimensions of the antenna. Generally the overall dimensions of the antenna is $30 \mathrm{~mm}$ by $90 \mathrm{~mm}$, the selected substrate for this structure is Roger RT/duroid 5880 with dielectric constant 2.2. In order to improve the impedance bandwidth performance for the antenna, a $10 \mathrm{~mm}$ by $10 \mathrm{~mm}$ slot has been placed on the ground plane under the radiating patch and a stacked patch supported with a metal wall height $4 \mathrm{~mm}$, which resulted in increasing the bandwidth of the antenna as can be seen in fig. 2. HFSS package is used to obtain the return loss and the radiation pattern.

Tab.1 Diminutions of the proposed patch antenna with shorting wall and slot (Unit mm)

\begin{tabular}{|c|c|c|c|c|c|}
\hline W0 & L0 & W1 & L1 & W2 & L2 \\
\hline 1.55 & 31.59 & 10.25 & 33 & 12 & 12 \\
\hline W3 & L3 & W4 & L4 & Ws & Ls \\
\hline 6 & 84 & 4 & 84 & 16 & 36 \\
\hline
\end{tabular}




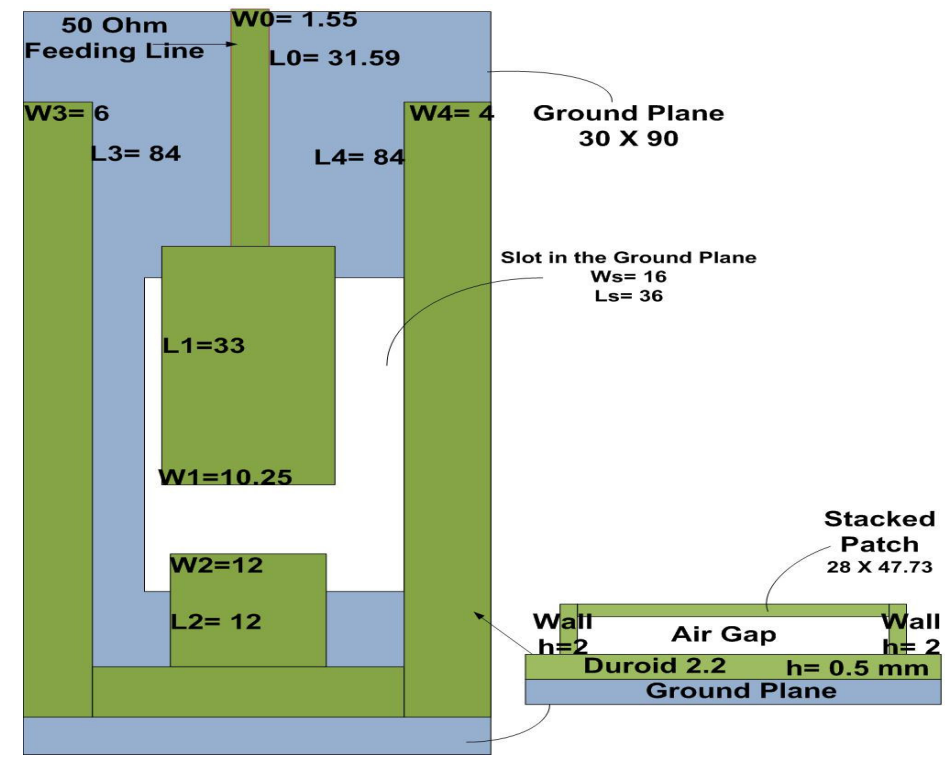

Fig. 1 Geometry of the patch antenna with shorting wall and slot (Unit: $\mathbf{m m}$ )

From fig. 2, it can be seen that the proposed antenna before adding the slot and the stacked patch has very narrow impedance bandwidth at $2.5 \mathrm{GHz}$. Whereas after placing the slot and the stacked patch the bandwidth has increased up to $25 \%$ at the centre of $2.8 \mathrm{GHz}$.

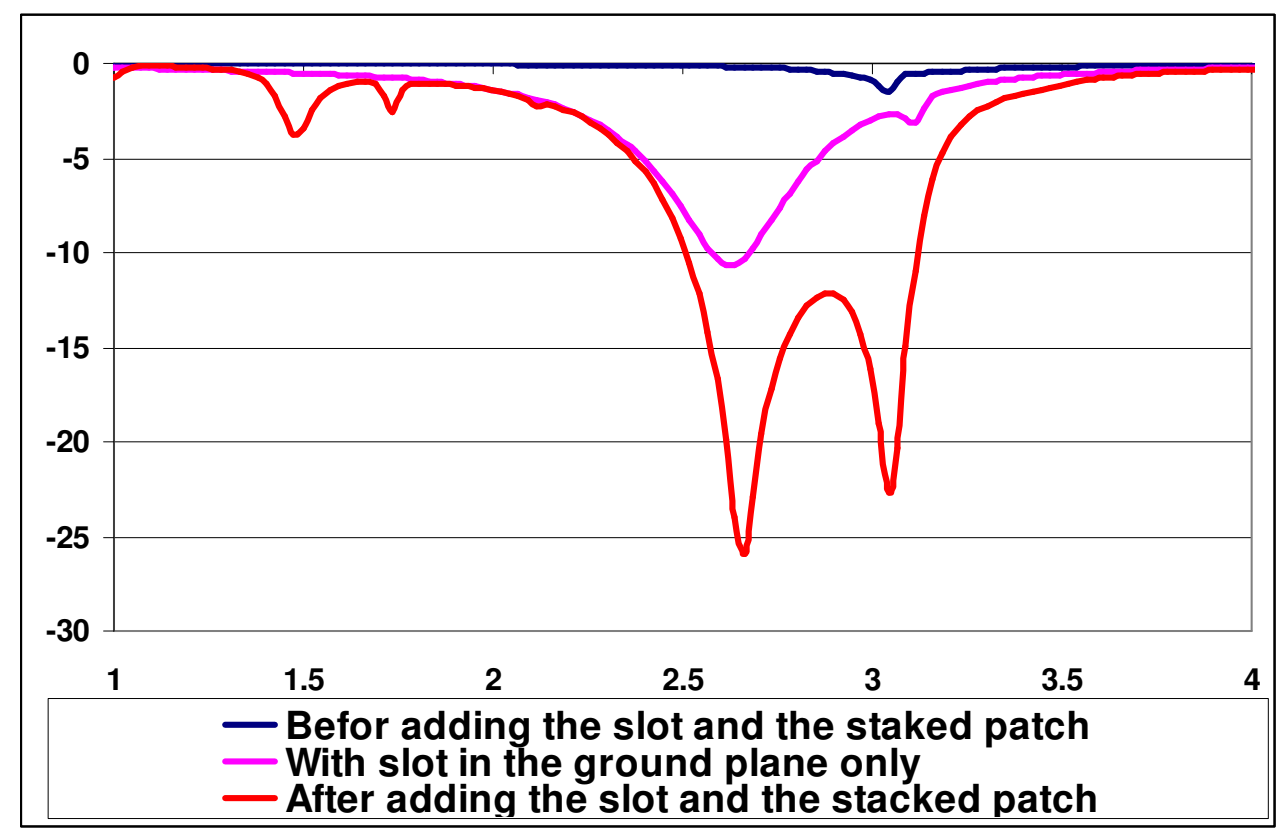

Fig. 2 Return loss response of the proposed antenna. 


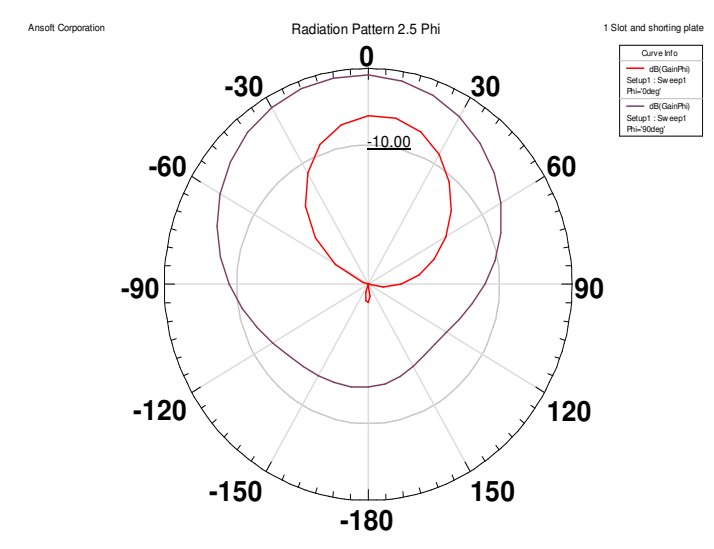

2.5 GHz Phi

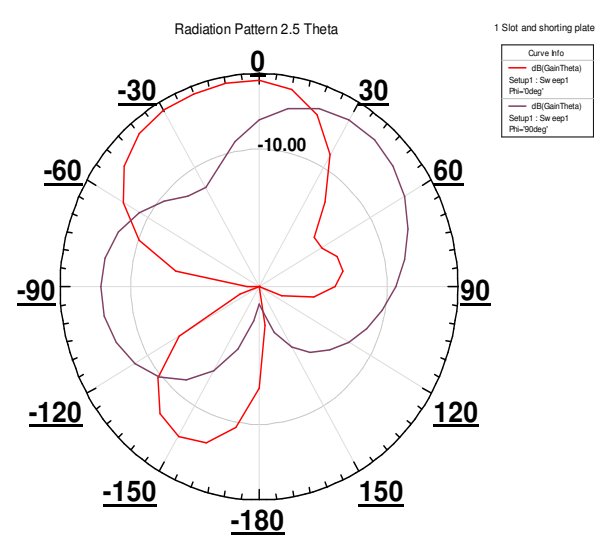

$2.5 \mathrm{GHz}$ Theta

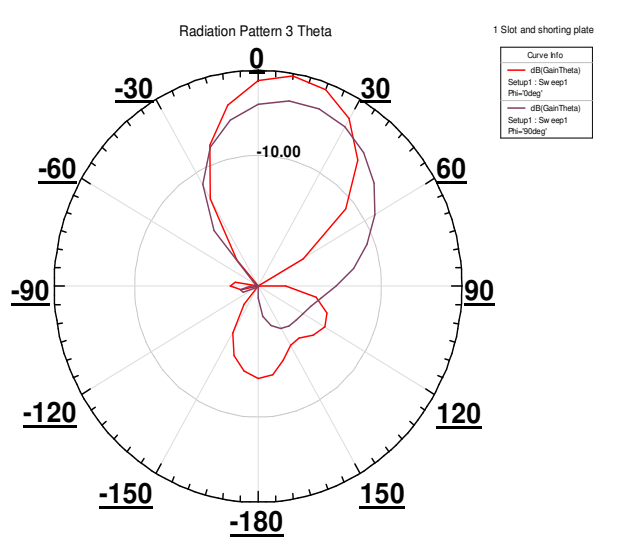

3.1 GHz Theta
3.1 GHz Phi

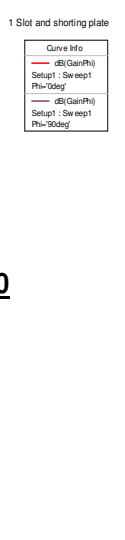

150

$-150$

$\underline{-180}$

Fig. 3 Radiation Pattern E-Plane and-H Plane: at $\mathrm{f}=2.5 \mathrm{GHz}$, and at $\mathrm{f}=3.1 \mathrm{GHz}$.

\section{CONCLUSION}

A small multi-band and wideband antenna has been introduced. Wideband has achieved by inserting slot on ground plane and stacked patch supported by wall for wireless application band $2.5 \mathrm{GHz}$ to $3.19 \mathrm{GHz}$. This antenna has a very simple structure printed on Duriod substrate. The total dimension of the ground plane is $30 \mathrm{X} 90 \mathrm{~mm}$. The antenna characteristic and radiation pattern are satisfactory for most of the wireless system.

\section{REFERENCES}

[1] W.L. Stutzman and G.A. Thiele, Antenna Theory and Design, 2nd ed. New York: Wiley, 1998

[2] C.A. Balanis, Antenna Theory, 2nd ed. New York: John Wiley \& Sons, Inc., 1997.

[3] H. F. AbuTarboush, H. S. Al-Raweshidy, "A Connected E-Shape and U-Shape Dual-Band Patch Antenna for Different Wireless Applications", the Second International EURASIP Workshop on RFID Technology, July, 2008.

[4] Nashaat DM, Elsadek H. Miniturized E-shaped dual band PIFA on FR4 substrates. Radio Science Conference, 2006 NRSC 2006 Proceedings of the Twenty Third National. 2006;0:1-6.

[5] FUJIMOTO T. Wideband stacked square microstrip antenna with shorting plates. IEICE Trans B: Communications. 2008 May 1;E91-B(5):1669-72. 
[6] Lin S-, Row J-. Bandwidth enhancement for dual-frequency microstrip antenna with conical radiation. Electronics Letters. 2008;44(1):2-3.

[7] Anguera J, Cabedo A, Picher C, Sanz I, Ribo M, Puente C. Multiband handset antennas by means of groundplane modification. Antennas and Propagation International Symposium, 2007 IEEE. 2007:1253-6.

[8] Mak CL, Chair R, Lee KF, Luk KM, Kishk AA. Half U-slot patch antenna with shorting wall. Electronics Letters. 2003;39(25):1779-80.

[9] H. F. AbuTarboush, H. S. Al-Raweshidy, R. Nilavalan, “Triple Band Double U-Slots Patch Antenna for WiMAX Mobile Applications", the 14th Asia-Pacific Conference on Communications , Japan, October 2008. 